\title{
Risk factors of Multidrug Resistant Tuberculosis in central Nepal: A pilot study
}

\author{
Marahatta $\mathrm{SB}^{1}$, Kaewkungwal $\mathrm{J}^{2}$, Ramasoota $\mathrm{P}^{3}$, Singhasivanon $\mathrm{P}^{4}$
}

${ }^{1}$ Ph.D Student, Department of Tropical Hygiene,

${ }^{2,4}$ Department of Tropical Hygiene,

${ }^{3}$ Department of Social and Environmental Medicine,

Faculty of Tropical Medicine Mahidol University, Thailand

\section{Corresponding Author}

Dr Pratap Singhasivanon

Department of Tropical Hygiene

Faculty of Tropical Medicine

Mahidol University

Thailand

Email.

Kathmandu Univ Med J 2010;9(32):392-7

\begin{abstract}
Introduction

Tuberculosis is the most widespread infectious disease in Nepal and poses a serious threat to the health and development of the country. Incidences of drug resistant tuberculosis in Nepal are increasing and this tuberculosisis a major threat to successfully controlling tuberculosis .
\end{abstract}

\section{Objective}

The general objective of the study was to assess the risk factors of multi-drug resistant tuberculosis among the patients attending the National Tuberculosis Centre, Bhaktpur Nepal.

\section{Methods}

An observational study/ case-control study with a Atotal number of 55 multi-drug resistant tuberculosis cases and 55 controls. The study was conducted among the patient attending in the National Tuberculosis Centre, Bhaktpur Nepal for six months, between May-October 2010. sImulti-drug resistant tuberculosis wasThe collected data was analysed in SPSS 11.5 version. The association between categorical variables were analysed by chi-square tests, $\mathrm{OR}$ and their $95 \% \mathrm{Cl}$ were measured.

\section{Results}

The total number of patients used for the study was 110, of which among them 55 were cases and 55 were controls. Our study revealed that there were significant associations between history of prior TB MDR-TB OR $=2.799$ (95\% Cl 1.159 to 6.667) $(p=0.020)$; smoking habit $O R=2.350$ and $(95 \% \mathrm{Cl} 1.071$ to 5.159$)(\mathrm{p}=0.032)$; social stigma social stigma OR $2.655(95 \% \mathrm{Cl}$ r 1.071 to 5.159$)(\mathrm{p}=0.013)$; knowledge on MDR-TB OR $=9.643(95 \% \mathrm{Cl} 3.339$ to 27.846$)(p<0.001)$ and knowledge on DOTS Plus OR=16.714 ( $95 \% \mathrm{Cl}$ is ranging from 4.656 to 60.008$)(p<0.001)$. However, there was no association found between alcohol drinking habits and ventilation in the room.

\section{Conclusion}

Our study revealed that there were significant associations between history of prior tuberculosis, smoking habit social stigma social stigma, knowledge on multidrug resistant tuberculosis and knowledge on DOTS Plus with multi-drug resistant tuberculosis However there was no association between alcohol drinking habit and ventilation in room with multi-drug resistant tuberculosis.

\section{Key Words}

directly observed treatment short course-plus, multidrug-resistant tuberculosis, risk factors 


\section{INTRODUCTION}

Although progress has been made to reduce global incidences of drug-susceptible tuberculosis, the emergenceofmultidrug-resistant(MDR)andextensively drug-resistant(XDR)tuberculosisduringthepastdecade threatenstounderminetheseadvances.Globally,in2008 alone,440,000 cases ofMDRtuberculosisaresaidtohave occurred. " Multi-drug resistant TB (MDR TB) in Nepal is a major threat for successful TB control. The NTP has carriedoutfoursentinelsitesurveillanceofdrugresistance innewtuberculosispatientssince1996aspartoftheWorld Health Organization (WHO) and International Union AgainstTuberculosisandLung Disease(IUATLD)global networkforsurveillance ofdrug resistanttuberculosis. Levels of drug resistance are high, with nearly $14.7 \%$ of newpatientsresistanttoatleastonedrug.LevelsofMDR TBarelow(2.9\%amongnewcases)and 11.7\%amongst previously treated cases. However, the pattern of drug resistanceinnewpatientsindicatesthelevelsofresistance whentheywereinfected, which mayhavebeen several years previously. Rifampicin resistance is low at $2.9 \%$ whilehigherprimaryresistanceistoisoniazid(8.4\%)and streptomycin (10.7\%). ${ }^{2}$ Many risk factors of MDR TB havebeenidentifiedinrecentpublications:previousTB treatment;irregulartreatment;gender;non-permanent residents; urbanmigration; urbanresidences;frequent travel; age; hygiene and sanitation; alcoholism; and smoking. ${ }^{3}$ Despitealltheseriskfactors, feworinadequate studieshavebeenconductedontheoccurrenceofMDR TB, particularly in Nepal. The purpose of this study is therefore,focusedsolelyonindentifyingtheriskfactors of MDR TB in central Nepal.

\section{METHODS}

Thisstudywasconductedamongthepatientsattending National Tuberculosis Centre, Bhaktpur Nepal. We conducted an unmatched, questionnaire-based case controlstudyamongstMDR-TBcasesandNon-MDRTB controlsthoseattendingtheNationalTuberculosisCentre (NTC) between May2010toOctober2010.Thepossible risk factors amongst MDR-TB cases and Non-MDRTBcases were studied.

\section{Selection of cases and control}

\section{Definition of case}

Anytuberculosiscasewith resistancetoboth ofthetwo majoranti-tuberculosisdrugs, IsoniazidandRifampicinis classifiedas anMDR-TBcaseas perthefinding ofadrug sensitivitytestandculturemethodfollowingtheprotocol of NTP of Nepal.
Identification of Cases

Identificationofthecaseswerecarriedoutthroughculture anddrugsensitivitytests.Cultureandsensitivitytesting was carried out at the GENETUP laboratory. Before processing, thespecimenswerekeptinarefrigeratorat $4^{\circ} \mathrm{C}$.Aftercentrifugationandwashing, thesedimentwas inculcated in tubes of $L J$ mediumandincubatedat $37^{\circ} \mathrm{C}$ fornineweeksoruntilcolonieswereobserved(whichever showedtheearliestsigns).Thedrugresistancetestswere performedbyusingtheproportionalmethod.Resistance tests to Rifampicin, Isoniazid, Streptomycin and Ethambutolwerecarriedout.Resistancewasexpressed as acertain percentage of colonies that grewoncritical concentrationsofthedrugs.Interpretationwascarriedout according to the usual criteria for resistance.

Source of the cases

The cases chosen were from diagnosed MDR cases recordedatany of thethreeDOTSPluscentresfromMay 2010 up to October 2010 (at the NationalTuberculosis Centre) and under their treatment. The risk factors associated with the cases were studied.

Definition of Control

Sputum positive tuberculosis cases undergoing DOTS treatmentforatleastfivemonthswithnegativefindingon sputum microscopy.

\section{Identification of Control}

Identification of control was conducted by using $\mathrm{ZN}$ staining for theidentification of Acidfastbacilli(AFB) in laboratory.

Thesource of control constituteshospital controls that were free from MDR tuberculosis i.e. sputum positive tuberculosispatientswhohadundergoneDOTStreatment foratleastfivemonthswithnegativefindingsonsputum microscopy. The controls were selected from the same centrediagnosedduringthesametimeframeasMDR-TB cases.

\section{MEASUREMENT OF RISK FACTORS}

Informationontheriskfactorswasassembledinprecisely the same manner for cases and control. Information wascollectedfromcasesand controlonawiderangeof potentialhostrelated,environmentalandhealthservice factors for MDR TB. These include many potential risk factors.Standardisedquestionnaireswereusedtostudy subjectsbyfieldassistantusingcolloquiallanguageafter checkingtheaccuracyoftranslationwiththeinterviewers.

DatawasenteredinSPSS 11.5versionforanalysis.Then theassociationsbetweencategoricalvariablewasassessed 
by Chi-square testing. Means and proportions were calculatedasappropriate.Unadjustedoddsratios(OR) and their $95 \%$ confidence intervals $(\mathrm{Cl})$ was estimated with MDR TB as an outcome. Univariate analysis was performedtomeasuretheeffectofeachvariableofinterest in risk of MDR TB.

\section{RESULTS}

Fifty-five patients with MDR TB and 55 Non-MDR TB patientsmadeupthecontrolgroupwereincludedinthe study. The mean age was 34.13 years in the MDRgroup and 32.09 years in econtrol group. Among the patients in the case group 36 (65.5\%) were male and 19 (34.5\%) werefemale. Amongstthecontrol41 (74.5\%)weremale and $14(25.5 \%)$ werefemale.Theanalyses ofthesex-wise distribution was divided by: geographic distribution, ethnicity, familytype,economicstatus andoccupation areshowninTable1.Table2belowshowstheassociation betweenhavingahistoryofpriorTBand therisk ofMDR TB.Thefindingrevealed thatthereisastrongassociation between having a history of prior TB with having MDR TB. The OR is found to be 2.799 ( $95 \% \mathrm{Cl} 1.159$ to 6.667 )
$(p=0.020)$.The association between a smoking habit is significantlyhighamongstMDR-TBcasesOR2.350and ( $95 \% \mathrm{Cl} 1.071$ to 5.159$)(p=0.032)$. Table 7 below shows theassociationbetweenhavinganalcoholdrinkinghabit and having MDR TB. The association between both is notsignificantlyhighwithOR0.554and $\mathrm{p}=0.126$ ). Table 7 below shows the association between social stigma and having MDRTB. The association between them is significantlyhigh with OR2.655(95\%Clr 1.071 to 5.159 ) $(p=0.013)$.Table7belowshowstheassociationbetween having ventilation in the room and being at risk of MDR TB.Theassociation between both is also notsignificant with OR 2.410 (95\%Cl ranging from 0.933-6.226) $(p=0.065)$.Table7belowshowstheassociationbetween knowledge on transmission of TB and risk of MDR TB. Theassociationbetweenthemisinsignificantlyhighwith OR0.654 ( $p=0.647)$.The knowledge regarding MDRTB is strongly associated with OR is $9.643(95 \% \mathrm{Cl} 3.339$ to 27.846) $(p<0.001)$. Likewise, the knowledgeregarding DOTS Plus and having MDR TB is strongly associated. $\mathrm{OR}=16.714(95 \% \mathrm{Cl}$ is ranging from 4.656to 60.008$)(\mathrm{p}<$ $0.001)$.

Table 1. Characteristics of cases \& controls

\begin{tabular}{|c|c|c|c|}
\hline Sex & Case & Control & Total \\
\hline Female & $19(34.5 \%)$ & $14(25.5 \%)$ & $33(30 \%)$ \\
\hline Male & $36(65.5 \%)$ & $41(74.5 \%)$ & $77(70 \%)$ \\
\hline \multicolumn{4}{|l|}{ Address } \\
\hline Mountain & $3(5.5 \%)$ & $1(1.8 \%)$ & $4(3.6 \%)$ \\
\hline Hilly & $43(78.2 \%)$ & $50(90.9 \%)$ & $93(84.5 \%)$ \\
\hline Terai & $9(16.4 \%)$ & $4(7.3 \%)$ & $13(11.8 \%)$ \\
\hline \multicolumn{4}{|l|}{ Ethnicity } \\
\hline Dalit & $4(7.3 \%)$ & $1(1.8 \%)$ & $5(4.5 \%)$ \\
\hline Disadvantaged Janjatis & $29(52.7 \%)$ & $20(36.4 \%)$ & $49(44.5 \%)$ \\
\hline Disadvantaged Non- Dalit Terai caste group & $1(1.8 \%)$ & $3(5.5 \%)$ & $4(3.6 \%)$ \\
\hline Religious Minorities & $0(0 \%)$ & $2(3.6 \%)$ & $2(1.8 \%)$ \\
\hline Relatively advantaged Janjatis & $5(9.1 \%)$ & $17(30.9 \%)$ & $22(20.0 \%)$ \\
\hline Upper caste Group & $16(29.1 \%)$ & $12(21.8 \%)$ & $28(25.5 \%)$ \\
\hline \multicolumn{4}{|l|}{ Type of Family } \\
\hline Nuclear & $46(83.6 \%)$ & $35(81 \%)$ & $81(73.6 \%)$ \\
\hline Joint & $7(12.7 \%)$ & $16(23 \%)$ & $23(20.9 \%)$ \\
\hline Extended & $2(3.6 \%)$ & $4(6 \%)$ & $6(5.5 \%)$ \\
\hline \multicolumn{4}{|l|}{ Occupation } \\
\hline Unemployed & $7(12.7 \%)$ & $2(3.6 \%)$ & $9(8.2 \%)$ \\
\hline Freelance employment & $15(27.3 \%)$ & $18(32.7)$ & $33(30.0 \%)$ \\
\hline Farmer & $7(12.7 \%)$ & $3(5.5 \%)$ & $10(9.1 \%)$ \\
\hline Service & $7(12.7 \%)$ & $11(20.0 \%)$ & $18(16.4)$ \\
\hline Student & $9(16.4 \%)$ & $11(20.0 \%)$ & $20(18.2 \%)$ \\
\hline Housewife & $5(9.1 \%)$ & $8(14.5 \%)$ & $13(11.8 \%)$ \\
\hline Other & $5(9.1 \%)$ & $2(3.6 \%)$ & $7(6.4 \%)$ \\
\hline
\end{tabular}




\begin{tabular}{|c|c|c|c|}
\hline \multicolumn{4}{|c|}{ Monthly Income of the Family } \\
\hline$<5000$ & $20(36.4 \%)$ & $10(18.2 \%)$ & $30(27.3 \%)$ \\
\hline $5000-10000$ & $11(20.0 \%)$ & 20(36.4\%) & $31(28.2 \%)$ \\
\hline $10000-15000$ & $7(12.7 \%)$ & $9(16.4 \%)$ & $16(14.5 \%)$ \\
\hline$>15000$ & $13(23.6 \%)$ & $10(18.2 \%)$ & $23(20.9 \%)$ \\
\hline Don't Know & $4(7.3 \%)$ & $6(10.9 \%)$ & 10(9.1\%) \\
\hline
\end{tabular}

Table 2. Comparison of the characteristics of MDR-TB and Non-MDR TB

\begin{tabular}{|c|c|c|c|c|c|}
\hline Group & & MDR TB & $\begin{array}{c}\text { Non MDR } \\
\text { TB }\end{array}$ & OR(95\% Cl) & $p$-value \\
\hline History of Prior Tuberculosis & $\begin{array}{l}\text { Yes } \\
\text { No }\end{array}$ & $\begin{array}{c}21(38.2 \%) \\
3(5.5 \%)\end{array}$ & $\begin{array}{c}10(18.2 \%) \\
3(3.6 \%)\end{array}$ & 2.779 (1.159 to 6.667$)$ & $0.020^{*}$ \\
\hline Smoking & $\begin{array}{l}\text { Yes } \\
\text { No }\end{array}$ & $\begin{array}{l}27(49.1 \%) \\
28(50.9 \%)\end{array}$ & $\begin{array}{l}16(29.1 \%) \\
39(70.9 \%)\end{array}$ & 2.350 (1.071 to 5.159$)$ & $0.032 *$ \\
\hline Alcoholic & $\begin{array}{l}\text { Yes } \\
\text { No }\end{array}$ & $\begin{array}{l}29(52.7 \%) \\
26(47.3 \%)\end{array}$ & $\begin{array}{l}21(38.2 \%) \\
34(61.8 \%)\end{array}$ & $0.554(0.259$ to 1.183$)$ & 0.126 \\
\hline Social Stigma & $\begin{array}{l}\text { Yes } \\
\text { No }\end{array}$ & $\begin{array}{l}34(61.8 \%) \\
21(38.2 \%)\end{array}$ & $\begin{array}{l}19(34.5 \%) \\
36(65.5 \%)\end{array}$ & 2.655 (1.223 to 5.765$)$ & $0.013^{*}$ \\
\hline Ventilation in Room & $\begin{array}{l}\text { Yes } \\
\text { No }\end{array}$ & $\begin{array}{c}47(85.5 \%) \\
8(14.5 \%)\end{array}$ & $\begin{array}{c}39(70.9 \%) \\
6(29.1 \%)\end{array}$ & $2.410(0.933$ to 6.226$)$ & 0.065 \\
\hline Knowledge on MDR TB & $\begin{array}{l}\text { Yes } \\
\text { No }\end{array}$ & $\begin{array}{l}27(49.1 \%) \\
28(50.9 \%)\end{array}$ & $\begin{array}{c}5(9.1 \%) \\
50(90.9 \%)\end{array}$ & 9.643 (3.339 to 27.846 ) & $<0.001 *$ \\
\hline Knowledge on DOTS PLUS & $\begin{array}{l}\text { Yes } \\
\text { No }\end{array}$ & $\begin{array}{l}27(49.1 \%) \\
28(50.9 \%)\end{array}$ & $\begin{array}{c}3(5.5 \%) \\
52(94.5 \%)\end{array}$ & 16.714 (4.656 to 60.008$)$ & $<0.001 *$ \\
\hline
\end{tabular}

\section{DISCUSSION}

Drug resistance is major problem in tuberculosis treatment. In Nepal, levels of drug resistance are very high, with nearly $14.7 \%$ of new patients resistant to at least one drug ${ }^{2}$ Previous treatment of tuberculosis has beenconsistentlyreportedastheriskfactorwithinvarious clinicalconditionsandpopulations. ${ }^{4-10}$ Thepresentstudy alsorevealedthatprevioustreatmentoftuberculosiswas strongly associated with MDR TB OR $=2.799(95 \% \mathrm{Cl}$ 1.159 to 6.667$)(p=0.020)$.According to the National TuberculosisProgramme'sNepalNationalSurveyin2007, MDR among new cases of TB is $2.9 \%$ and MDR among previouslytreatedcasesisat $11 \%$ therebygivingaratioof approximately4:1 forprevalenceofMDRinthesegroups, ${ }^{2}$ this pattern holds truein ourstudy too. Lomtadzeet.al. determined previously administered TB treatment as an important risk factor for the development of drug resistanceTBandreported thatthissituationincreased developmentofdrugresistancebyfivetimesonaverage. ${ }^{11}$ AstudybyFaustineet.al.hasshownthatpreviousantiTBtreatmentwasthestrongestdeterminantofMDR-TB in Europe. MDR-TB patients were more likely to have received previoustuberculosistreatmentin 22 studies, with a pooled riskestimate of being 10 times higherfor treatedcasesthanfornewpatients. ${ }^{12}$ Likewise,Mendoza et.al.reportedthatpreviousTBtreatmentformorethan
threemonthsincreasedtheriskofMDRTB. ${ }^{13}$ Baghaeiet. al.alsoreported thatapositivehistory ofpreviousanti-TB medicationwassignificantlyhigherintheMDR-TBgroup compared to the non-MDR-TB controls $(p=0.001) .^{14}$ Another study revealed that the risk of MDR in people previouslygivenTBtreatmentwas 10.54timeshigherin those who were not given treatment. ${ }^{15} \mathrm{Clark} C M$ et. al. hasshownthatpriortreatmentofTBwasindependently associated with MDR-TB with OR $=8.3795 \% \mathrm{Cl}$ ranging between3.92to17.89. ${ }^{16}$ Likewiseanotherstudyfoundthat patients with MDRTBweremorelikely to havereceived previoustreatmentoftuberculosiscomparedtopatients with non-MDRTB (58.3\% vs. $16.2 \%, P=0.002) .{ }^{17}$ A study carried outinChinafound that patientswith a previous treatmenthistorywasmorethanfivetimeslikelytohave an increased risk of MDR-TB (adjusted OR: $6.14,95 \% \mathrm{Cl}$ : 4.61-8.17),comparedwiththosepreviouslywhohadnot beentreated. ${ }^{17}$ Aretrospectivecohortstudyconductedin Spainrevealedthatprevioustreatmentfortuberculosis as a risk factor for MDR TB with (OR: $3.44 ; 95 \% \mathrm{Cl}$ : $1.58-7.50 ; p=0.003) .{ }^{18} \mathrm{~A}$ prospective epidemiological case control study conducted in Europe found that previoustuberculosistreatmentwasfoundtobethemost significantriskfactorforMDR-TB. ${ }^{19}$ Previous treatment for tuberculosis has been consistently associated with 
MDR-TB. ${ }^{20}$ Itcanalsobeconcluded thatpriortreatment fortuberculosisisthemostsignificantriskfactorforMDRTB. The strengthening of DOTS programme and close monitoringoftuberculosispatientsseemstobethemost promisingendeavourtopreventthedevelopmentofMDR TB.

Ourstudyrevealedthattheassociationbetweenhaving a history of smoking and MDRTB was significant with OR 2.350 and $95 \% \mathrm{Cl}$ ranging from 1.071 to 5.159 $(p=0.032)$. A study done in western Nepal on the risk factors of MDR TB revealed that 74\% of the MDR-TB patientshadahistoryofsmoking (pastaswellaspresent). ${ }^{20} \mathrm{~A}$ study carried out in Pakistan revealed that MDR had shown strong associations with smoking (13\%) as compared to non-smokers (5.6\%) $(p<0.05) .{ }^{21}$ Also in anotherstudy,smokingappearedasoneoftheriskfactors for MDR TB. ${ }^{22}$ Smoking was found to be associated withisoniazidresistancebutmoreevidenceisneeded to explainthisassociation. ${ }^{24} H$ owever, astudyconductedin Korea amongstthemilitaryworkerfoundnosignificant differences in terms of smoking history $(P=0.658) .{ }^{24} \mathrm{In}$ North India, of the risk factors studied for MDR-TB, tobaccosmoking hadnorelationtoinfection withMDR. ${ }^{25}$ Whetherornotsmokingincreasesthechanceofdrug resistance in tuberculosis is yet to be unveiled.

Ourfinding infers that theassociation between having an alcohol drinking habit and having MDR TB is not significantOR=0.554 ( $p=0.126)$. LikewiseinNorth India, of the riskfactorsstudiedforMDR-TBexcessivealcohol intake, hadnorelationtoinfectionwithMDR. ${ }^{25}$ Thestudy doneinSpainsuggeststhatpatientswithalcoholabuseare lesslikelytohaveMDR-TB.Thisisanunexpectedfinding, since alcoholism has been associated with treatment default and poor treatment outcome among patients withTBinothercountries, althoughsomestudiescould not find a higher risk of MDR-TB in alcoholic patients. ${ }^{18}$ Alcoholabuse/dependencewasassociatedwithaneightfold increase in drug resistance $(\mathrm{OR} 8.58 ; 95 \% \mathrm{Cl} 2.09$ 35.32). ${ }^{26}$ Inamultivariableanalysis, alcoholconsumption duringtreatmentwasfoundtobethestrongestpredictors of poor treatment outcome for MDR TB. ${ }^{39}$ In another study, alcoholismappearedasoneoftheriskfactorsfor MDR TB. ${ }^{22}$

Socialstigmaandlackofscientificawarenessaboutthe diseaseand social commitments are stated reasonsfor interrupting and defaulting TB treatment.In ourstudy, association between social stigma and having MDRTB is significant with OR $2.655(95 \% \mathrm{Cl} 1.071$ to 5.159$)$ $(\mathrm{p}=0.013)$

Ourstudyrevealedthattheassociationbetweenhaving ventilation in the room and the risk of MDRTB is found tobeslightlyinsignificantOR2.410(95\%Clrangingfrom 0.933-6.226) ( $p=0.065)$. Poor housing, overcrowding and homelessness are clear risk factors for MDR TB in theTerairegionofNepal. ${ }^{27}$ Anotherstudyrevealedthata lowernumberofroomsinthehousecanalsobeassociated with MDR TB. ${ }^{22}$

Althoughafullknowledgeoftuberculosistransmission and spectrum of disease are not crucial in finishing a courseofmedicine,itisareflectionofhowwellpatientsare beingeducatedabouttheirillness.Knowledgeregarding MDRTB and DOTS Plus was significantly high amongst MDRTB patients. This reflects that the patients are well informedregardingMDRTBandDOTSPlusduring their treatment.

The association between TB and poverty has been known for centuries, and this also applies to MDR-TB, a rathersignificantinverseassociation between MDRTB andfamily income. ${ }^{22}$ Largercasecontrol studies will be requiredtodeterminewhetherornotthesocio-economic factorsandpoorknowledgeleadingtopooradherenceto treatmenttherebyleadingtothedevelopmentofMDR-TB are proven.

\section{CONCLUSION}

Many risk factors of MDR TB have been identified in recent publications. Ourstudy revealed that there was a significant association between having a history of priorTB, a smoking habit, social stigma, knowledge of MDR TB and knowledge of DOTS Plus with MDR TB. However, therewasnoassociation between having an alcohol drinking habitand ventilation in theroom. The strength and truthfulness of theses associations need to beexamined with a multi-centre case-control study sothat riskfactors can be unveiled. Such studies can be designedonthebasisofthefindingsofthepresentstudy. Thefindingsofsuchstudiescould offerstrongimpetusto strengthentheDOTSPlusprogrammeandmayprove to be fruitful in reducing MDR TB burden in Nepal.

\section{ACKNOWLEDGEMENT}

The authors would like to acknowledgeWHO/TDR for providing financial support to carry out the study. We wouldalsoliketogivethanks toMrRoshanMahatoand hisfriendsfortheirsupportthroughtheirlaboratorywork and collection of data. Thanks goes to Sagar Ghimire, Senior Public Health Administrator MoHP, staffs of NationalTuberculosiscentreincludingformerDirector Dr Puspha Malla and Dr K.K Jha for their kind help. Likewise, thanksgoestoDrBhawanaShresthaandstaff ofthelaboratorydepartmentofGENETUPforproviding laboratoryfacilitiestocarryoutthecultureandDSTtests of the MDR TB patients. 


\section{REFERENCES}

1. GandhiNR,Nunn P,DhedaK,SchafS,ZignolM,Soolingen DV et al Multi drug resistant and extensively resistant tuberculosis:athreattoglobalcontroloftuberculosisLancet 2010;375:1830-43

2. The Government of Nepal Ministry of Health and Population. Drug -Resistant Tuberculosis management guidelines and manual 2010.p.1-99.

3. CamineroJAMultidrug-resistanttuberculosis:epidemiology, riskfactorsandcasefindingsInt JTubercLung2010;14:38290.

4. RuddyM,BalabanovaY,GrahamC,Fedorinl,Malomanova $\mathrm{N}$,Elisarova E,et al Rates of drug resistance and riskfactor analysisincivilianand prison patientswithtuberculosisin Samara Region, Russia. Thorax 2005;60:130-5.

5. Choi JC, Lim SY, Suh GY,Chung MP, Kim H, Kwon OJ et al Drug resistance rates of Mycobacterium tuberculosis at a private referral center in Korea. J Korean Med Sci 2007;22:677-81.

6. LeeJH,ChangJH.Drug-resistanttuberculosisinatertiary referral teaching hospital of Korea. Korean J Intern Med 2001;16:173-9.

7. Kim SY, Jeong SS, Kim KW, Shin KS,Park SG,Kim AK et al. Drug-resistantpulmonarytuberculosisinatertiaryreferral hospital in Korea. Korean J Intern Med 1999;14:27-31.

8. Granich RM, Oh P,Lewis B,Porco TC, Flood J. Multidrug resistanceamong personswithtuberculosisinCalifornia, 1994-2003. JAMA 2005;293:2732-2739.

9. Arevalo M, Solera J, Cebrian D, Bartolome J, Robles P. Riskfactorsassociated withdrug-resistantMycobacterium tuberculosis in Castilla-la-Mancha (Spain). Eur Respir J 1996;9:274-8.

10. Chung MJ, Lee KS, Koh WJ, Kim TS, Kang EY, Kim SM et. al. Drug-sensitive tuberculosis, multidrug-resistant tuberculosis,andnontuberculousmycobacterialpulmonary diseaseinnon-AIDSadults:comparisonsofthin-sectionCT findings. Eur Radiol 2006;16:1934-41.

11. LomtadzeN,AspindzelashviliR,JanjgavaMet.al.Prevalance andriskfactorsformultidrug-resistanttuberculosisinthe RepublicofGeorgia:apopulationbasedstudy.IntJTuber Lung DIs 2009;13:68-73

12. Faustini A, Hall AJ, Perucci CA Risk factors of multidrug resistanttuberculosisinEurope:asystematicreviewThorax 2006;61:158-63

13. Mendoza MT, Gonzaga AJ, Roa C et. al. Nature of drug resistanceandpredictorsofmultidrug-resistanttuberculosis among patients seen at Philippine General Hospital, Manaliam Phillipines Int JTuberc Lung Dis 1997;1:59-63

14. BaghaeiP,TabarasiP,ChitsazEet.al.Riskfactorsassociated with multidrugresistanttuberculosisTanaffos 2009;8:1721.
15. KliimanK,AltrajaAPredictorsofextensivelydrugresistant pulmonarytuberculosisAnnInternMed2009;150:766-75.

16. Clark CM Li J, Driver CR, Munsiff SS Risk factors for drugresistanttuberculosisamongnon-US-bornpersonsinNew York City Int J Tuberc Lung Dis 2005;9;964-9.

17. Shao A, Yang D, Xu W, Lu W, Song H, Dai $Y$ et al. Epidemiology of Anti-tuberculosis Drug Resistance in a Chinese Population: Current Situation and Challenges Ahead BMC Public Health 2011;11:110.

18. Suarez-Garcia I, Rodriguez-Blanco A, Vidal-Perez JL, Garcia-Viejo MA, Jaras-HernandezMJ,LopezOet.al.Risk factorsformultidrug-resistanttuberculosisinatuberculosis unit in Madrid, Spain Eur J Clin Microbiol Infect Dis. 2009 ;28:325-30.

19. CasalM,Vaquero M, RinderH, et.al.ACase-ControlStudy forMultidrug-ResistantTuberculosis:RiskFactorsinFour European Countries. Microb Drug Resist 2005;1: 62-9.

20. PantR,PandeyKR,JoshiM,SharmaS,PandeyT,PandeyS. Riskfactorassessment of Multi-drug ResistantTBJNHRC 2009;7:89-92.

21. Khan Ahmad, Usmani AQ, Sultana A, Hussian Z, Khan DARisk factor in development of MDRTbin hospitalised patients Pakistan Armed Force Medical Journal 2005;4

22. Barroso EC, Salani Mota, RM, Santos RO, et al. Riskfactors foracquiredmultidrug-resistanttuberculosisJPneumologia 2003; 29:989-97.

23. Ruddy M , Balabanova Y,Graham C et. al. Rates of drug resistance and risk factor analysis in civilian and prison patientwithtuberculosisinSamaraRegion, RussiaThorax 2005;60:130-5.

24. Lee SW, Jeon K, Kim KH, Min KH Multidrug-resistant PulmonaryTuberculosisAmongYoungKoreanSoldiersina Communal Setting J Korean Med Sci 2009;24:592-5.

25. PandeJN,SinghUB,SinhaSet.al.Evaluation ofriskfactors and prevalenceofdrugresistanttuberculosisinNorthlndia. Chest 2002;128:404

26. Fleming MF, KrupitskyE, Tsoy M Zvartau E, Brazhenko N, JakubowiakWet. al. Alcohol and drug use disorders, HIV statusanddrugresistanceinasampleofRussianTBpatients Int J Tuberc Lung Dis 2006;10:565-70.

27. Department of Health Services, Government of Nepal. AnnualReportFY064/065.DepartmentofHealthServices; 2008. 